\title{
Perspectives of elderly people receiving home help on health, care and quality of life
}

\author{
YIva Hellström ${ }^{1}$ RNT and I. R. Hallberg ${ }^{2}$ RNT DMSc \\ ${ }^{1}$ Department of Science and Health, Blekinge Institute of Technology, SE-371 79 Karlskrona, Sweden and ${ }^{2}$ Department of \\ Nursing, Unit of Caring Sciences, Lund University, PO Box 198, SE-221 00 Lund, Sweden
}

\author{
Correspondence \\ Ylva Hellström \\ Department of Nursing \\ Unit of Caring Sciences \\ Lund University \\ PO Box 198 \\ SE-221 00 Lund \\ Sweden \\ E-mail: ylva.hellstrom@omv.lu.se
}

\begin{abstract}
From a nursing perspective it is important to have information about the type of care needed, the reasons care is needed and quality of life among the most elderly people living in their own homes, in order to support their independence and maximise their quality of life. Thus a study was performed to investigate people aged 75 years and older dependent on care from professionals and/or a next of kin, their functional health, diseases, and complaints in relation to quality of life as perceived by themselves. The sample $(n=448)$ comprised those who, in an age-stratified randomised sample of adults living in their own homes, responded that they were dependent on help from others. The questionnaire covered sex, age, living conditions, civil status and number of children and cohabitation, respondents' health, diseases, quality of life, help from another person, and the type and amount of help received. The number of elderly persons dependent on help ranged from 18.5 to $79.1 \%$ in the different age groups. The help came mainly from informal carers $(84.1 \%)$, and, in $53.1 \%$ of cases, from the home help service and home nursing care. Help from formal caregivers was given in combination with that from a next of kin in $38.8 \%$ of the cases. More next of kin than formal carers helped in all Instrumental Activities of Daily Living (IADL) and Personal Activities of Daily Living (PADL) tasks, with the exception of cleaning the house and providing a bath/shower. Although the respondents received help themselves, they also helped another person in $6.5 \%$ of cases. The elderly reported a median of three diseases and ten different complaints of which pain and impaired mobility were the most frequent. Between 20 and $40 \%$ of the respondents in the different age groups reported restricted ability to be alone and one third of them reported low or very low quality of life. Multiple linear regression analysis showed the number of complaints, restricted ability to be alone, living alone and age to have a significant relationship on low quality of life.
\end{abstract}

Keywords: 75+ years, dependency, formal care, home care, home help, informal care

Accepted for publication 9 November 2000

\section{Introduction}

Knowledge about elderly care recipients living in their own homes will become increasingly important as the number of very old people increases. This is true both for Sweden and for most other Western countries (Statistics Sweden (SCB) 1997). In Sweden this increase in the number of old people coincides with a shrinking economy leading to a decrease in the number of elderly people cared for in nursing homes and sheltered accommodation and using the state subsidised home help service. In 1993, 23 per cent of adults aged 80 years or over received public home help service. By 1997 this had shrunk to 20 per cent, despite a greater number of people of this age (The National Swedish Board of Health \& Welfare 1999, Statistics Sweden (SCB) 1997). 
Demographic and economic change may lead to increased care-giving demands on families. Research in Sweden into family care-giving is limited and rather out of date considering the rapidity of change. As early as 1991, Johansson and others demonstrated that informal care-giving in Sweden was, as in other countries, extensive (Johansson 1991, Orbell 1996, Repetto et al. 1997). In Sweden this occurred despite the fact that elderly people have the right to receive public services and care if needed (The Swedish Institute 1996). Elderly people received care from family and friends, from the public care services or from both (Johansson 1991, Orbell 1996). In his study of people $>75$ years of age living at home, Johansson (1991) found, by calculating the total costs based on hours for services provided per year and excluding combined help, that informal care was as least twice as extensive as formal care. In Britain and Sweden, elderly people mostly needed help with shopping, transportation, financial and legal matters, housework and bathing or showering (Johansson 1991, Orbell 1996). Grown-up children or other relatives were the most common informal helpers (Johansson 1991, Orbell 1996). Swedish studies on informal and formal care for older people are based on data mostly collected from before the economic cutbacks. It is reasonable to assume that more demands have been put on the elderly and on the family due to the shrinking economy.

From a nursing perspective, the type of care needed and the reasons care is needed are of particular interest. Old age per se does not put the elderly in need of care. It is more the fact that elderly people living to an advanced age suffer illnesses, handicaps and functional impairments that make them dependent on care and help in their daily living (Thorslund et al. 1991, Österlind 1993). Old peoples' experience of diseases and impairments also threaten their quality of life (Grimby \& Svanborg 1997). Studies highlighting the type of care needed and the reasons behind the need for care are, however, sparse; particularly studies that focus on the elderly person's own perception of the impact of care on quality of life (Olivius et al. 1996). This is striking, as such knowledge is needed to determine appropriate care, to train professional carers, and to provide support to informal carers, and also because only the care recipients themselves can report on their quality of life (Nolan et al. 1996). In a Swedish study (Olivius et al. 1996), the majority of elderly persons (aged 65 years and over) cared for in their own homes by an informal carer were over 80 years old, and each person in most cases had several diseases, principally related to the circulatory system as well as mental and behavioural disorders. One third of them were dependent in three or more of the Katz ADL categories (Activities of Daily Living). Mobility and memory were the most frequent problems. The demands for home care were found to be related to the elderly person's medical diagnosis, his/ her ability to be alone and functional health status. Thus, knowledge about elderly peoples' medical condition, functional health status and need for continuous supervision is important for outlining support from and for collaboration with the primary caregivers.

Meeting the needs of the increasing number of very old people is often said to be achievable through collaboration between formal and informal care (Herlitz \& Dahlberg 1999). Such collaboration requires knowledge about the type and frequency of family care-giving that already exists. Primary health care staff and/or home help service staff are supposed to have knowledge about the living conditions of the elderly within their catchment area. The study by Olivius et al. (1996), however, indicated that the home care service staff knew only some of those cared for at home by a family member.

The fact that only a few studies focus on informal care in Sweden can be explained by the fact that responsibility for care of the elderly rests with the public sector (The Swedish Institute 1996). In times when the economy was good, people could rest assured that the provision of public care was sufficient to meet the needs of the elderly. Thus, updated knowledge is required about the need for care, the reasons behind the need for care in the elderly and about who is providing the care. This knowledge needs to be derived from the care recipient's perspective in order to reflect their view of their situation.

\section{Objectives}

The aim of this study was to investigate, in one municipality, those aged 75 years or more, living in their own homes and dependent on care from others for their health (including Instrumental ADL and Personal ADL) and their quality of life, the help they require and from where the help came. The aim was also to make age and gender comparisons of these aspects.

\section{Methods and materials}

\section{The Swedish context}

The main guiding concept in care of the elderly in Sweden is to enable them to remain in their own homes as long as possible (The Swedish Institute 1996). An alternative form of housing (sheltered accommodation) is to be available for those who are no longer able to live at home. Such accommodation may be in the form of sheltered housing, old people's homes, nursing homes or group dwellings for people with dementia (The Swedish Institute 1996). In 1997, 23 per cent of all Swedish residents aged 80 and over were living in 
Table 1 The population, sample, response rate and elderly people dependent on help in their daily living

\begin{tabular}{lcclc}
\hline Age & $75-79$ & $80-84$ & $85-89$ & $90-99$ \\
\hline Population $(n)$ & 2824 & 2058 & 978 & 365 \\
Target sample $(n)$ & 847 & 617 & 294 & 108 \\
Response rate $(\%)$ & $486(57.3)$ & $448(72.3)$ & $223(75.5)$ & $91(84.3)$ \\
Dependent $(\%)$ & $90(18.5)$ & $161(35.9)$ & $125(56.0)$ & $72(79.1)$ \\
\hline
\end{tabular}

dwellings for elderly people (The National Swedish Board of Health and Welfare 1999). The Swedish system of national pensions is designed to give elderly people financial security. Health care and medical services are state subsidised (The Swedish Institute 1996).

\section{Sample}

The sample for this study comprised 448 adults (mean $=84.1$ years, S.D. $=5.1$ ). A questionnaire was addressed to an age-stratified randomised sample of adults aged 75 or over, living in their own home in a southern Swedish municipality; those in the sample responded that they were dependent on help from others (need of help from 'several times a week' to 'not every week') for their daily living. Another 29 adults responded that they were dependent. However, they were excluded because they did not answer the question about the kind of help they required and from whom. The municipality had about 70000 inhabitants of whom $3.6 \%$ were 75 years or over ( $n=6225 ; 38 \%$ men and $62 \%$ women). Thirty per cent were randomised from those between 75 and 79, 80 and 84,85 and 89,90 and 94, and $95>$ years of age. Due to the small number in the two oldest groups, these two age groups were combined into one (90-99 years) (Table 1). There was no-one over 99 years of age living in their own home. Those who were 75 years or over and lived in sheltered accommodation $(10.6 \%, n=737)$ were excluded from the total sample. The target sample number was 1866 , and the response rate $67 \%(n=1248)$. Reasons for not participating were for example 'too old', 'not feeling well', 'do not have anything to say', or 'do not want to participate'. There was a significantly higher drop out ( $P$-value $<0.001$, chi-squared test) in the youngest age group (75-79) compared to the oldest (90-99) (Table 1), but no significant difference between dependent men and women with regard to response rate.

\section{Instrument and procedure}

A postal questionnaire, covering the respondent's health, complaints (Figure 1), diseases (based on classification, World Health Organisation 1992), quality of life (Table 2), ability to be alone (in eight levels from 'cannot be alone at all' to 'manage by my self'), help from another person (informal helper as relatives, friends/

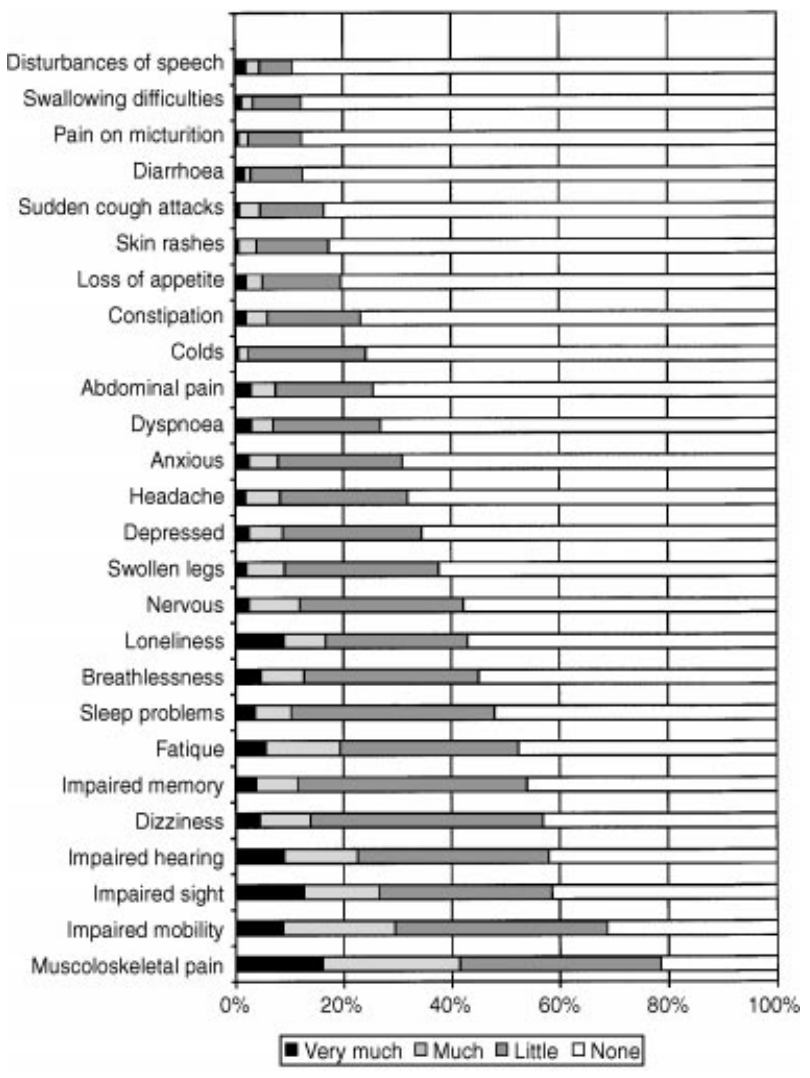

Figure 1 Percentage and severity of complaints reported as present over a 3-month period.

neighbours, non-profit organisation or formal helper as home help service and home nursing care), the type of help they received (IADL and PADL) (Tables 3 and 4) and how much help was received, was sent to the target sample. For this purpose a new 'quality of life' variable was constructed by adding the responses to each question concerned with quality of life. The scores on the summed quality of life questions could range from 8 to $28($ mean $=17)$. The questionnaire also covered demography facts such as sex, age, number of children, living conditions (countryside, village and city), civil status (married, widowed, single and divorced) and cohabitation (alone, together with husband/wife, together with grown up children). The respondents were instructed to get help from relatives or the home help service if they were unable to respond by themselves and if they did so to indicate who helped them to complete the questionnaire. 
Table 2 The respondent's view (\%) about quality of life

\begin{tabular}{|c|c|}
\hline & $\%(n=448)^{*}$ \\
\hline \multicolumn{2}{|l|}{ How do you feel at present? } \\
\hline Very good/good & 66.5 \\
\hline Bad/very bad & 30.6 \\
\hline \multicolumn{2}{|l|}{ What is your experience of life today? } \\
\hline Very good/good & 70.7 \\
\hline Bad/very bad & 24.3 \\
\hline \multicolumn{2}{|c|}{ Do you usually think life could be less monotonous? } \\
\hline Seldom/never & 60.7 \\
\hline Very often/often & 34.8 \\
\hline \multicolumn{2}{|c|}{$\begin{array}{l}\text { Do you usually feel depressed about one day being like } \\
\text { another? }\end{array}$} \\
\hline Seldom/never & 63.8 \\
\hline Very often/often & 31.7 \\
\hline \multicolumn{2}{|c|}{ I am just as happy and satisfied as when I was younger } \\
\hline No & 42.4 \\
\hline Do not know & 27.2 \\
\hline Yes & 23.4 \\
\hline \multicolumn{2}{|l|}{ My life could be more eventful than it is now } \\
\hline Yes & 43.1 \\
\hline Do not know & 22.3 \\
\hline No & 25.9 \\
\hline \multicolumn{2}{|l|}{ These are the best years of my life } \\
\hline No & 57.1 \\
\hline Do not know & 20.5 \\
\hline Yes & 10.0 \\
\hline \multicolumn{2}{|l|}{ I am very satisfied with my life at present } \\
\hline No & 25.9 \\
\hline Do not know & 27.0 \\
\hline Yes & 40.0 \\
\hline Summated score for quality of life mean (sd) & $17.69(0.24)$ \\
\hline
\end{tabular}

* Age of respondents $=75-99$ years.

Internal missing varied between 13 and 55 cases.

Chronbach's alpha coefficient $=0.87$.

This was to ensure that those who could not read, write or communicate were not excluded. Help from another person was needed by $68.1 \%$, mostly from relatives (66.2\%) and from the home help service (18.7\%). One reminder was sent. Questionnaires returned with 'address unknown' or where the person had moved to a service home or had died were randomly replaced from the same age group.

\section{Statistical methods}

The Chi-square test was used to analyse the response rate in relation to age groups. The relationship between age groups and nominal data such as gender, living condition, civil status, cohabitation, type of complaints, help with IADL, help with PADL, and type of help received was analysed using the Chi-square test. The relationship between age groups and gender and variables such as 'helping another person', 'managing to be alone', 'receiving help from another person' and quality of life questions was analysed using the Kruskal-Wallis one-way ANova test. Every single complaint was divided into 'no complaint' and 'some complaint' (little, much or very much) and the relationship to 'quality of life' was analysed by means of the Mann-Whitney $U$-test. Cronbach's alpha test was used for measuring internal consistency of quality of life questions. A multiple linear regression analysis (Enter selection) was used to find the variables explaining 'quality of life' (dependent variable). Independent variables were gender, cohabitation, number of diseases, number of complaints, civil status, age, PADL help and IADL help and the ability to be alone. Civil status was categorised into 'married', 'widower', 'unmarried or divorced', the first two being the standard. Type of help was categorised into 'formal help only', 'both informal and formal help', and 'informal help only', the first two being the standard. For the statistical analysis SPSS for Windows 95, version number 8.0 was used (SPSS Inc. SPSS for Windows 1998).

\section{Results}

The number of dependent elderly ranged from $18.5 \%$ in the younger age group to $79.1 \%$ in the eldest age group $(P$-value $<0.001)$ (Table 1$)$. There were significant differences in the age groups regarding gender, civil status, cohabitation, and ability to be alone (Table 5). There were significantly more widows (67.7) than widowers (25.7) $(P$-value $<0.001)$. Also, the older the respondents were, the less time they could spend alone ( $P$-value $<0.01)$. Although the respondents were dependent themselves, $6.5 \%$ of the total sample helped another person on a daily basis (Table 5).

\section{Diseases}

The number of diseases ranged from none (8.5\%) to 14 (median $=3, q 1 / q 3=2 / 5$ ). There were no significant differences in number or type of diseases with regard to age. Significantly more women than men had metabolic diseases (women, $10.2 \%$; men, $2.6 \%$; $P$-value $<0.01$ ) and hypertension (women, 26.5\%; men, 15.1\%; P-value $<0.01$ ), while men had significantly more cerebrovascular diseases (men, $10.5 \%$; women, $4.8 \%$; $P$-value $<0.05$ ) and bronchitis (men, $17.1 \%$; women, $10.2 \%$; $P$-value $<0.05$ ) (Table 6).

\section{Complaints}

The number of complaints ranged from none (2.7\%) to $26(0.2 \%)($ median $=10, \mathrm{q} 1 / \mathrm{q} 3=6 / 13)$. Men with no complaints comprised $4.6 \%(n=7)$ of all men and 
Table 3 The type of help provided to the respondents $(\%)(n=448)$ for the age groups and for Instrumental ADL, Personal ADL activities and for technical and medical matters

\begin{tabular}{|c|c|c|c|c|c|c|}
\hline Age & $\begin{array}{l}75-79 \\
(n=90)\end{array}$ & $\begin{array}{l}80-84 \\
(n=161)\end{array}$ & $\begin{array}{l}85-89 \\
(n=125)\end{array}$ & $\begin{array}{l}90-99 \\
(n=72)\end{array}$ & $\begin{array}{l}\text { Total } \\
(n=448)\end{array}$ & $P$ value \\
\hline Help with Instrumental ADL (\%) & 87.8 & 88.8 & 92.0 & 98.6 & 91.1 & \\
\hline Cleaning & 80.6 & 85.7 & 91.9 & 97.1 & 88.5 & $0.04^{*}$ \\
\hline Shopping & 73.9 & 80.8 & 82.1 & 91.2 & 81.8 & \\
\hline Bank and/or post office business & 64.6 & 69.3 & 73.5 & 88.1 & 73.2 & $0.03^{*}$ \\
\hline Weekly washing & 57.9 & 54.3 & 71.2 & 80.4 & 64.7 & $0.04^{*}$ \\
\hline Transfer to the bus & 41.4 & 51.5 & 53.0 & 83.3 & 54.7 & $0.01^{*}$ \\
\hline Cooking & 46.2 & 46.4 & 51.4 & 54.9 & 49.4 & \\
\hline Transfer outdoors & 35.9 & 38.5 & 43.2 & 61.1 & 43.1 & $0.02^{*}$ \\
\hline Telephone the hospital & 28.6 & 37.7 & 34.7 & 49.3 & 37.1 & \\
\hline Help with Personal ADL (\%) & 40.0 & 42.2 & 52.0 & 62.5 & 47.8 & \\
\hline Bathing/showering & 35.4 & 40.3 & 49.5 & 61.0 & 45.8 & $0.01^{*}$ \\
\hline Remembering things & 35.4 & 34.2 & 27.2 & 40.3 & 33.5 & \\
\hline Dressing & 22.6 & 23.9 & 18.2 & 27.5 & 22.6 & \\
\hline Transfer indoors & 7.8 & 14.7 & 16.5 & 26.3 & 16.1 & \\
\hline Going to toilet & 7.8 & 8.3 & 9.6 & 15.7 & 10.0 & \\
\hline Transfer to/from bed & 4.8 & 11.7 & 6.9 & 14.1 & 9.5 & \\
\hline Using the toilet & 3.2 & 8.2 & 5.8 & 11.1 & 7.2 & \\
\hline Turning over in bed & 3.2 & 7.2 & 3.9 & 7.8 & 5.6 & \\
\hline Eating & 4.7 & 3.6 & 5.8 & 6.4 & 5.0 & \\
\hline Help with medical matters (\%) & 27.8 & 31.1 & 44.0 & 45.8 & 36.4 & $0.01^{*}$ \\
\hline Injections, medicines, dressings, etc. & 40.4 & 42.2 & 51.9 & 53.9 & 47.0 & \\
\hline Medical technical equipment & 6.5 & 4.9 & 6.5 & 10.0 & 6.5 & \\
\hline
\end{tabular}

Chi-squared test was used to analyse data of age groups and variant kind of help. ${ }^{*} P<0.05$.

Table 4 Type of help provided with regard to formal and informal helpers

\begin{tabular}{|c|c|c|c|c|c|}
\hline & \multicolumn{3}{|c|}{ Informal helper } & \multicolumn{2}{|l|}{ Formal helper } \\
\hline & $\begin{array}{l}\text { Relatives } \\
\%\end{array}$ & $\begin{array}{l}\text { Friends/neighbours } \\
\%\end{array}$ & $\begin{array}{l}\text { Non-profit } \\
\text { organisation \% }\end{array}$ & $\begin{array}{l}\text { Home help service } \\
\%\end{array}$ & $\begin{array}{l}\text { Home nursing care } \\
\%\end{array}$ \\
\hline \multicolumn{6}{|l|}{ Help with IADL } \\
\hline Shopping & 54.2 & 6.9 & 0.2 & 12.5 & - \\
\hline Bank and/or post office business & 48.0 & 5.6 & - & 5.5 & - \\
\hline Weekly washing & 37.5 & 3.4 & - & 14.9 & - \\
\hline Cleaning & 33.5 & 4.0 & - & 44.6 & - \\
\hline Telephone the Hospital & 23.2 & 1.6 & - & 3.8 & 0.9 \\
\hline Cooking & 22.8 & 1.3 & 0.4 & 14.0 & - \\
\hline Transfer outdoors & 18.3 & 3.5 & - & 9.7 & 0.2 \\
\hline Transfer to the bus & 17.9 & 2.0 & - & 4.9 & - \\
\hline \multicolumn{6}{|l|}{ Help with PADL } \\
\hline Remembering things & 18.3 & 2.0 & - & 3.8 & 0.2 \\
\hline Bathing/showering & 15.8 & 0.9 & - & 18.3 & - \\
\hline Dressing & 11.4 & 0.4 & - & 9.3 & 0.9 \\
\hline Transfer indoors & 5.8 & 0.4 & - & 2.8 & - \\
\hline Going to toilet & 4.0 & - & - & 2.4 & - \\
\hline Transfer to/from bed & 3.8 & 0.6 & - & 2.0 & - \\
\hline Using the toilet & 2.7 & - & - & 1.8 & - \\
\hline Turning over in bed & 2.2 & 0.2 & - & 1.3 & - \\
\hline Feeding & 2.2 & 0.2 & - & 1.5 & - \\
\hline \multicolumn{6}{|l|}{ Help with medical matters } \\
\hline Injections, medicine & 13.6 & 0.7 & 0.4 & 6.5 & 12.7 \\
\hline Medical technical equipment & 1.8 & - & 0.2 & 1.8 & 2.4 \\
\hline
\end{tabular}




\begin{tabular}{|c|c|c|c|c|c|}
\hline Age & $\begin{array}{l}75-79 \\
(n=90)\end{array}$ & $\begin{array}{l}80-84 \\
(n=161)\end{array}$ & $\begin{array}{l}85-89 \\
(n=125)\end{array}$ & $\begin{array}{l}90-99 \\
(n=72)\end{array}$ & $P$ value \\
\hline \multicolumn{6}{|l|}{ Gender (\%) } \\
\hline Female/male & $62.2 / 37.8$ & $66.3 / 33.8$ & $59.7 / 40.3$ & $80.6 / 19.4$ & 0.02 \\
\hline \multicolumn{5}{|l|}{ Living conditions (\%) } & 0.9 \\
\hline Countryside & 17.8 & 15.8 & 12.2 & 15.3 & \\
\hline Village & 20.0 & 24.1 & 25.2 & 19.4 & \\
\hline City & 62.2 & 60.1 & 62.6 & 65.3 & \\
\hline \multicolumn{5}{|l|}{ Civil status (\%) } & 0.00 \\
\hline Married & 49.4 & 42.0 & 27.2 & 9.7 & \\
\hline Widowed & 34.8 & 46.5 & 60.8 & 79.2 & \\
\hline Single & 9.0 & 7.0 & 10.4 & 9.7 & \\
\hline Divorced & 6.7 & 4.5 & 1.6 & 1.4 & \\
\hline \multicolumn{5}{|l|}{ Children } & 0.9 \\
\hline Mean (S.D.) & $2.2(1.6)$ & $2.3(1.6)$ & $2.2(1.7)$ & $2.3(1.9)$ & \\
\hline \multicolumn{5}{|l|}{ Cohabitation (\%) } & 0.00 \\
\hline Alone & 51.1 & 57.7 & 68.5 & 80.6 & \\
\hline With husband/wife & 46.7 & 39.2 & 24.2 & 8.3 & \\
\hline With children & 2.2 & 1.9 & 4.0 & 8.3 & \\
\hline With another person & - & 3.2 & 3.2 & 2.8 & \\
\hline \multicolumn{5}{|c|}{ Helping another relative or friend (\%) } & 0.3 \\
\hline Every day & 9.6 & 5.9 & 7.6 & 4.2 & \\
\hline Sometimes & 4.8 & 2.7 & 3.1 & 1.4 & \\
\hline \multicolumn{5}{|c|}{ Manage to be alone at home without help (\%) } & 0.001 \\
\hline All the time & 46.9 & 40.8 & 26.3 & 17.6 & \\
\hline From 4 to 7 days & 18.5 & 9.5 & 18.6 & 19.1 & \\
\hline From 1 to 3 days & 8.6 & 15.0 & 19.5 & 16.2 & \\
\hline From 13 to 23 hours & 3.7 & 6.8 & 5.1 & 5.9 & \\
\hline From 1 to 12 hours & 18.5 & 21.1 & 22.9 & 30.9 & \\
\hline Cannot be alone at all & 3.7 & 6.8 & 7.6 & 10.3 & \\
\hline
\end{tabular}

Table 5 Characteristics of the respondents $(n=448)$ and comparison for age groups (\%)

Internal missing varied between 2 and 8 cases. In 'Helpinganother sick relative or friend' 23 cases were missing.

women, $1.7 \%(n=5)$ of all women. The main complaints were musculoskeletal pain (78.6\%) and impaired mobility $(68.8 \%)$ (Figure 1$)$. People in the older age groups reported more problems with loss of appetite $(P$-value $<0.05)$, impaired sight ( $P$-value $<0.001)$, impaired hearing $(P$-value $<0.001)$ and loneliness $(P$-value $<0.01)$ compared to younger age groups. Women stated significantly more often than men that they suffered loss of appetite (women, $23.5 \%$; men, $13.2 \%$; $P$-value $<0.01$ ), swollen legs (women, 43.5\%; men, 26.3\%; $P$-value $<0.001$ ), sleep problems (women, $52.7 \%$; men, $38.2 \%$; $P$-value $<0.01$ ), feeling nervous (women, $46.3 \%$; men, $33.6 \%$; $P$-value $<0.01$ ), feeling anxious (women, $36.7 \%$; men, 19.1\%; $P$-value $<0.001$ ) and loneliness (women, $46.3 \%$; men, $32.2 \%$; $P$-value $<0.001)$. Women stated a significantly higher grade of depression $(P$-value $<0.01)$ and suffered more loss of appetite $(P$-value $<0.05)$ than men. Men stated significantly more often than women that they had speech disturbances (men, $15.1 \%$; women, $8.8 \%$; $P$-value $<0.05)$.

\section{Quality of life}

Between $60.7 \%$ and $70.7 \%$ of the sample stated that they had a good or very good quality of life (Table 2). There were no significant differences between gender, civil status or cohabitation in relation to quality of life. Elderly persons who suffered from musculoskeletal pain, abdominal pain, loss of appetite, constipation, dyspnoea, fatigue, sleep problems, anxiety, nervousness, depression and feeling lonely had a significantly lower degree of quality of life than those who did not have these complaints ( $P$-value $<0.001)$. Reduced memory $(P$-value $<0.001)$, reduced mobility, reduced sight, headache $(P$-value $<0.01)$ and swallowing difficulties, swollen legs, disturbances of speech and diarrhoea also caused a significantly lower degree of quality of life $(P$-value $<0.05)$ than in cases were these complaints were not present. Complaints that did not influence low quality of life were reduced hearing, dizziness, depression, breathlessness, colds, skin rashes, 
Table 6 Frequency (\%) of diseases and comparison for gender $(n=448)$

\begin{tabular}{lccl}
\hline & $\begin{array}{l}\text { Female } \% \\
(n=294)\end{array}$ & $\begin{array}{c}\text { Male } \% \\
(n=152)\end{array}$ & $\begin{array}{l}\text { Pvalue } \\
\text { for gender }\end{array}$ \\
Diseases & 47.6 & 42.8 & 0.3 \\
\hline Musculoskeletal disease & 36.7 & 40.8 & 0.4 \\
Other circulatory disease & 35.4 & 33.6 & 0.7 \\
Eye disease & 26.5 & 15.1 & $0.006^{*}$ \\
Hypertension & 18.4 & 23.0 & 0.2 \\
Heart attack & 13.9 & 14.5 & 0.9 \\
Disease of the joints/arthritis & 12.2 & 14.5 & 0.5 \\
Diabetes Mellitus & 10.2 & 17.1 & $0.04 \dagger$ \\
Bronchitis/emphysema/ & & & \\
Asthma/other respiratory disease & 9.9 & 15.8 & 0.07 \\
Urogenital disease & 10.5 & 12.5 & 0.5 \\
Infections & 12.6 & 7.9 & 0.1 \\
Hip fracture & 9.5 & 9.9 & 0.9 \\
Ear disease & 10.2 & 7.2 & 0.3 \\
Rheumatic disease & 8.8 & 9.2 & 0.9 \\
Gastrointestinal disease & 6.8 & 11.2 & 0.1 \\
Dermatosis & 10.2 & 2.6 & $0.004^{*}$ \\
Metabolic disease & 7.5 & 7.2 & 0.9 \\
Other neuropathy disease & 4.8 & 10.5 & $0.02 \dagger$ \\
Cerebrovascular disease & 7.5 & 4.6 & 0.2 \\
Other psychiatric disease & 5.4 & 4.6 & 0.7 \\
Dementia & 4.8 & 3.9 & 0.7 \\
Hepatic and biliary disease & 3.4 & 5.9 & 0.2 \\
Tumour & 4.4 & 2.6 & 0.4 \\
Blood/haematological disease & 3.1 & 4.6 & 0.4 \\
Multiple sclerosis/Parkinson's disease & 1.4 & 0.7 & 0.5 \\
Congenital defect disease & 13.8 & 0.6 \\
Other diseases & & & \\
\hline & & & \\
\hline
\end{tabular}

Internal missing $=2$ cases. Chi-squared test was used to analyse diseases and gender. ${ }^{*} P<0.01 ; \dagger P<0.05$.

\begin{tabular}{lrll}
\hline Variables & B & $95 \%$ confidence interval & $P$ value \\
\hline Number of complaints & 0.423 & $(.333 .513)$ & 0.000 \\
Not able to stay at home without help & 0.466 & $(.264 .667)$ & 0.000 \\
Age & -0.160 & $(-0.243,-.077)$ & 0.000 \\
Only formal help & 5.010 & $(.477,9.543)$ & 0.030 \\
Both informal and formal help & 5.163 & $(.763,9.564)$ & 0.022 \\
Living alone & 0.940 & $(-0.001,1.881)$ & 0.050 \\
\hline
\end{tabular}

Variables with no significant influence were, gender, IADL, PADL, number of diseases, widowhood, married.
Table 7 Variables associated with quality of life (linear regression) sudden cough attacks and pain on micturition. The linear regression analysis showed that age, number of complaints, living alone and the ability to be alone were significantly associated with a low quality of life (Table 7).

\section{Help provided}

The amount of help received with PADL was significantly higher in the older $(P$-value $<0.05)$ compared to the younger age groups (Table 8 ). Men reported significantly more help with IADL $(P$-value $<0.001)$ than women. People in the older age groups stated that they received significantly more help with regard to cleaning, bank and/or post office business, weekly washing, transfer to bus and transfer outdoors, and men reported significantly more help than women with cleaning $(P$-value $<0.001)$, weekly washing $(P$-value $<0.001)$, cooking $(P$-value $<0.001)$ and shopping $(P$-value $<0.01)$. People in the older age groups also reported significantly more help with bathing/showering than those in the younger age groups (Table 3 ) and men had more help with dressing $(P$-value $<0.05)$ than women. 


\begin{tabular}{lcllrl}
\hline Age & $\begin{array}{l}75-79 \\
(n=90)\end{array}$ & $\begin{array}{l}80-84 \\
(n=161)\end{array}$ & $\begin{array}{l}85-89 \\
(n=125)\end{array}$ & $\begin{array}{l}90-99 \\
(n=72)\end{array}$ & P value \\
\hline $\begin{array}{l}\text { Help with Instrumental ADL } \\
\quad \text { Several times a week }\end{array}$ & 38.9 & 44.1 & 46.0 & 51.4 & 0.07 \\
At least once a week & 34.4 & 30.4 & 33.9 & 43.1 & \\
$\quad$ Not every week & 26.7 & 27.2 & 20.2 & 4.2 & \\
Help with Personal ADL & & & & & \\
$\quad$ Several times a week & 15.6 & 12.4 & 14.8 & 25.4 & 0.011 \\
At least once a week & 12.2 & 18.0 & 23.0 & 22.5 & \\
Not every week & 2.2 & 6.2 & 9.0 & 5.6 & \\
\hline
\end{tabular}

Kruskal-Wallis test was used for statistical analysis.

\begin{tabular}{lcccc}
\hline & $\begin{array}{l}\text { Less or about } \\
\text { once a week \% }\end{array}$ & $\begin{array}{l}2-3 \text { days } \\
\text { a week \% }\end{array}$ & $\begin{array}{l}4-6 \text { days a week } \\
\text { or every day \% }\end{array}$ & Total \% \\
\hline $\begin{array}{llll}\text { Informal help } \\
\quad \text { Wife/husband }\end{array}$ & 9.6 & 2.0 & 22.1 & 33.7 \\
$\quad$ Children/spouses of the child & 38.2 & 7.6 & 9.6 & 55.4 \\
$\quad$ Friends/neighbours & 15.0 & 2.0 & 3.1 & 20.1 \\
Total informal help & 50.2 & 11.2 & 32.1 & 84.1 \\
Formal help & & & & \\
$\quad$ Home help service & 24.6 & 6.3 & 17.0 & 47.8 \\
$\quad$ Home nursing care & 18.1 & 2.0 & 3.1 & 23.2 \\
Total formal help & 37.7 & 8.3 & 18.5 & 53.1 \\
\hline
\end{tabular}

Table 8 The received help $(n=448)$ in age groups and for Instrumental ADL and Personal ADL activities (\%)
Table 9 Informal and formal helpers with regard to whom and how often help was provided
In all, 38.8\% $(n=174)$ respondents had informal as well as formal help, while $45.3 \%(n=203)$ had only informal help and $14.3 \%(n=64)$ had only formal help. The total number of elderly people receiving informal help was $84.1 \%(n=377)$ and formal help, $53.1 \%$ $(n=238)$ (Table 9). Children helped parents significantly more often in the older age groups $(P$-value $<0.01)$ than in the younger age groups. Wives helped husbands significantly more often $(P$-value $<0.001)$ than husbands helped wives. Women had home help service significantly more often than men did ( $P$-value $<0.01)$. Informal helpers helped the elderly more than formal helpers in all IADL items except for cleaning and also in all PADL variables except for bathing/showering. Mostly formal helpers handled medical matters, mainly those from home nursing care. Relatives, however, handled medical matters approximately to a similar extent as home nursing care (Table 4).

\section{Discussion}

The aim of this study was to investigate the frequency of care received in the homes of people aged 75 years and older provided by professionals and/or a next of kin, their functional health, diseases, complaints and quality of life as perceived by the elderly. Depending on their age, between 18.5 and $79 \%$ of the elderly living in their own homes had help either for IADL or PADL activities. Although they themselves had help, between 5 and 10 per cent of the cases also provided help every day for a relative or friend. Their health problems were, as might be expected, related mainly to the cardiac and circulatory systems or the musculoskeletal system and their main complaints were pain, mobility restrictions, impairments in hearing and sight, fatigue and also problems related to memory impairment and dizziness. About one third of the sample reported low or very low quality of life in most of the items, thus reflecting their view of their current quality of life. In $20-40 \%$ of the cases the respondents judged their ability to be alone as ranging from not at all to less than 12 hours, and in 4$10 \%$ of cases they thought that they could not be alone at all. The help came mostly from family members or another next of kin. Only 53\% of the sample received formal care and this was in combination with help from a next of kin in $38.8 \%$ of cases. Where help was provided often or almost every day, spouses contributed mostly to care-giving, whilst in cases of less frequent help the children were the most common helpers. Factors of significant importance for low quality of life were 
number of complaints, ability to be alone, living alone and age.

The strength of this study was that it was population based. The sample was drawn from a medium-sized city in Sweden. Because this study is based on only one municipality and each municipality is independent when it comes to decisions about provision care for the elderly, the findings may not be representative of all municipalities. The overall response rate was acceptable, but low for people between 75 and 79 years of age, and increasingly higher the older the target sample was. It is likely that the lower drop-out rate in the younger respondents was because they felt well and felt that the questionnaire was not relevant to their life situation. For the remaining sample the drop-out was probably related to being in a worse state. Thus, the findings may be skewed in a too negative direction for the youngest respondents and in a slightly too positive direction for the remaining age groups. Bearing this limitation in mind, however, it seems likely that these findings reflect quite well the situation of the oldest people living in their own homes in medium-sized Swedish municipalities. This interpretation is supported by the fact that demographic details such as the number of elderly living alone, the gender distribution and the distribution of formal care service were consistent with other population-based studies focusing on these age groups (Almind et al. 1991, Grimby \& Svanborg 1997).

The findings in this study are based on a questionnaire that was previously developed and tested in a smaller population-based study. Questions relating to complaints and help were developed and used in earlier studies (Tibblin et al. 1990) or were based on ICD classification of diseases (World Health Organisation 1992). The questions relating to quality of life were not entirely taken from a standardised measure, and that may represent a shortcoming. Only a sample of the questions relating to quality of life was used (Nordbeck 1996). Thus, comparisons with other studies are difficult. Research indicates that one single item reflecting the respondents' quality of life has a high predictive value for aspects like survival (Liang 1984). In all the items used concerning quality of life a fairly coherent picture emerged of $25-30 \%$ stating low quality of life. The summated score on these items showed an acceptable Cronbach's alpha indicating consistency in the responses. A selection of items, rather than an entire quality of life measure was used as a result of not wanting to include too many questions and thereby jeopardising the internal response rate. So as to secure the response rate people were also asked to get help from another person if they felt unable to answer by themselves. Quite a large amount of respondents got help from a family member $(66.2 \%)$ and a smaller number from a formal carer
(18.7\%). This directive has its pros and cons. The helper may have influenced their responses. Such influence may, however, go in both directions, i.e. helping the elderly to get facts straight and/or influencing them in their subjective responses in one way or another. It seems however, fair to state that steps have been taken to secure the reliability and validity of this study.

The findings of this study indicate that the majority of care of the elderly takes place in the homes of the elderly. The total number of old people cared for in sheltered accommodation/nursing homes in Sweden is $23 \%$ of those aged 80 years or older. There are no figures available for the country regarding those aged 75 years or above. In the municipality focused on in this study, $10.6 \%$ lived in sheltered or similar accommodation. The numbers dependent on help among those living in their own houses ranged from $18.5 \%$ to $79.1 \%$ for the different age groups. Thus, the number of elderly people who received help in their own homes was considerably greater than for those in sheltered accommodation. This is in accordance with the official policy for care of the elderly, the main reason for this strategy being that it is best for the elderly to remain in their own homes (The Swedish Medical Research Council (MFR) 1987). Whether or not this is beneficial for the elderly cannot be judged from this study, because the sample did not include people in sheltered accommodation or nursing homes. The findings do, however, indicate the need to acknowledge that addressing the needs of the elderly cared for at home may be equally important or even more important than addressing the needs of those in sheltered accommodation. In this study the home nursing care staff apparently had very little contact with the sample and the home help service only had contact with about $50 \%$ of them. It may well be that economic benefits could accrue from more closely monitoring these families in terms of increased quality of life for the families. This, however, requires paying regular home visits to very old people (Hendriksen et al. 1984).

In a country with a supposedly well developed and state-subsided system of care for the elderly this study reveals that care is mainly provided within the family or their larger social network. This was the most striking, although not surprising, finding from this study. A family member or a spouse were the most common helpers with regard to help on a daily basis, and children or their spouses for less frequent provision. The patterns of family care resemble international as well as national studies, i.e. it is mostly among elderly couples that the most demanding informal care takes place and children are more involved in care of women then of men (Orbell 1996). These findings are probably related more to the longevity of women than to the issue of gender. It is also worth noting that every tenth of the respondents had 
help from a friend or neighbour. Thus, the social network in a wider sense was involved in providing help, mostly the IADL type. The vast majority of the respondents (84.1\%) had informal help rather than receiving formal help $(53.1 \%)$, either from the home help service or home nursing care. There are no comparable data available in Sweden due to the lack of studies focusing on informal care-giving. Johansson (1991), however, stated that, calculated in hours, informal care was twice as extensive as formal care. These findings did not include combined help and home nursing care. In this study almost $40 \%$ had combined help whilst only $14.3 \%$ had formal help only and $45.3 \%$ had informal help only. Although comparisons cannot be made, it seems fair to state that the contribution from the next of kin is far greater than that from formal care-giving, including home nursing care (Table 3). It may well be that Johansson's results are an underestimation or that the shrinking economy has already contributed to a greater input from informal carers. Whatever the case, these findings indicate the need for a family approach in care of the elderly.

The findings in this study have important clinical implications for the care of the elderly. The formal caregiving system was in contact with no more than half of the respondents; thus, the other half did the best they could on their own. There may be a risk that people in the public health care system feel assured that they have sufficient knowledge about the elderly living in their own homes and that the people they provide help for are those most in need. Olivius et al. (1996) showed that, on the contrary, neither those in charge of home help services nor those in charge of home nursing care seemed to have sufficient knowledge about the elderly within their area of responsibility. Hendriksen et al. (1984) found that regular home visits, by a district nurse for instance, to the elderly at aged 75 years or over contributed significantly to reduce acute hospital care and improved quality of life in comparison to a control group. These findings were further supported in a meta-analysis bringing together all studies concerning applying an intervention in the form of systematic home visits from professionals to the elderly (Rademacker Jensen 1997). Thus, the role of primary health care, and especially the district nurses, may be critically important for the elderly receiving help from a next of kin.

From the findings it seems that the families are handling medical problems, probably in some cases severe conditions. Almost all the elderly reported at least one disease and in most cases several diseases, which probably played a major role in their depending on help. The median figure was three diseases reported per person (ranging from 0 to 14). They also reported a number of complaints (median 10/person, range $0-26$ ). The number of complaints contributed significantly to a low quality of life, as did the presence of almost every kind of complaint. These results suggest that their health was, at least in some cases, poor, and in third of the sample it led to low or very low quality of life, which was further exacerbated by feelings of loneliness and a depressed mood. The severity of their condition may be reflected by the fact that between 3.7 and $10.3 \%$ could not be alone at all and between 18.4 and $30.9 \%$ were restricted in how many hours they could be alone. The necessity of having another person present may be due to cognitive decline or other severe restrictions. It does, however, put strain on the carer (Thorslund et al. 1991, Herlitz \& Dahlberg 1999). These findings also indicate the necessity of preparing or advising family members about handling complicated medical problems. This is to be contrasted to the fact that only half of the sample had regular contact with the home nursing care. They may, however, have had regular contact with physicians or hospital care or may not wish to have any contact with the public care system.

The families had a prominent role in the care of the elderly, which highlights the role of the professional carers as educators and partners or coworkers (Nolan et al. 1996). A shift in attitude among professional carers may be needed, from that of being providers to that of being partners and sharing knowledge with informal carers. The type of knowledge needed relates to the diseases and their manifestations, the handling of functional restrictions and ways of preventing or easing the burden of complaints that restrict the quality of life of respondents. The type of help provided followed the order in which people lose their functional abilities, i.e. IADL activities became restricted and to a greater extent than those of PADL. Also the need for help with PADLs follows the way these functional abilities are lost, i.e. eating was the best preserved ability (Sonn 1995). Without doubt, the next of kin had the main responsibility in all IADL and PADL tasks, with the exception of cleaning the house and providing a bath/shower. It was not uncommon for one elderly person in need of help to help another fragile elderly person. They also took great responsibility in providing help with medical matters such as injections, distribution of pills and handling technical medical equipment. The type of complaints and diseases reported resembles those in other studies, i.e. the main problems are pain, immobility, impaired sight and hearing, and accordingly the most common diseases were related to the heart and circulatory system or the muskuloskeletal system and most of the elderly had several diseases (Österlind 1993). This situation with multiple diseases and complaints contributes to lower quality of life but also to a more vulnerable situation. Thus, knowledge about nursing care related to 
these complaints and diseases is of the outmost importance for those involved, i.e. family members, in the care of the elderly and it is therefore surprising that the elderly had so little contact with the home nursing care.

It seems fair to state that a considerable number of those in need of help from others also had a low quality of life. To our knowledge, no previous studies have focused on the quality of life in those cared for at home. Demographic aspects such as gender and cohabitation did not contribute to a low quality of life. Factors that did contribute were rather the number of complaints, age, living alone and not being able to be at home alone. The fact that as many as approximately one third of the sample reported low quality of life lends further importance to the need to monitor those of the elderly who live in their own homes and receive help from others, and to support the informal helpers.

\section{Acknowledgements}

We are grateful to the participants of this study. This study was supported by County Council of Kristianstad and the Freemasons of Skåne, Skånska Provinsiallogen. We are grateful to Patricia Shrimpton, University of Umeå, for revising the English.

\section{References}

Almind G., Holstein B., Holst E. \& Due P. (1991) Old persons' contact with general practitioner in relation to health: a Danish population study. Scandinavian Journal of Primary Health Care 9, 252-258.

Grimby A. \& Svanborg A. (1997) Morbidity and health-related quality of life among ambulant elderly citizens. Aging (Milano) 9, 356-364.

Hendriksen C., Lund E. \& Strömgård E. (1984) Consequences of assessment and intervention among elderly people: a three year randomised controlled trial. British Medical Journal 289, 1522-1524.

Herlitz C. \& Dahlberg L. (1999) Causes of strain affecting relatives of Swedish oldest elderly. Scandinavian Journal of Caring Sciences 13, 109-115.

Johansson L. (1991) Caring for the Next of Kin. On Informal Care of the Elderly in Sweden. Acta University, Uppsala, Stockholm.
Liang J. (1984) Dimensions of the Life Satisfaction Index A: a structural formulation. Journal of Gerontology 39, 613-622.

Nolan M., Grant G. \& Keady J. (1996) Understanding Family Care. Open University Press, Philadelphia.

Nordbeck B. (1996) Quality of Life And Satisfaction Among Centenarians. Gerontology Research Centre, Lund.

Olivius G., Hallberg I.R. \& Olsson B. (1996) Elderly care recipients in a Swedish municipality living in their own homes: their diseases, functional health status and care provided as reported by formal carers. Health and Social Care in the Community 4, 133-141.

Orbell S. (1996) Informal care in social context: a social psychological analysis of participation, impact and intervention in care of the elderly. Psychology and Health 11, 155-178.

Österlind P.O. (1993) Medical and Social Conditions in the Elderly Gender and Age differences: The Umea Longitudinal Study. University of Umeå, Umeå.

Rademacker Jensen G. (1997) Forebyggende hjemmebesög til äldre mennesker. En vurdering af kontrollerede interventionsstudier (in Danish). Ugeskrift for Laeger 159, 6358-6361.

Repetto L., Granetto C. \& Venturino A. (1997) Home care in the older person. Clinics in Geriatric Medicine 13, 403413.

Sonn U. (1995) Longitudinal studies of dependence in daily life activities among the elderly. Department of Rehabilitation Medicine and Department of Geriatric Medicine. University Gothenburg, Göteborg.

SPSS Inc. SPSS for Windows (1998) Base System, Professional Statistics, and Advanced Statistics, Version 8.0. SPSS Inc., Chicago.

Statistics Sweden (SCB) (1997) Statistisk årsbok (in Swedish). Statistiska Centralbyrån, Stockholm.

The National Swedish Board of Health and Welfare (1999) Vård och omsorg om äldre och personer med funktionshinder (in Swedish). Socialstyrelsen, Stockholm.

The Swedish Institute (1996) The Care of the Elderly in Sweden. The Swedish Institute, Stockholm.

The Swedish Medical Research Council (MFR) (1987) Kunskapsbehov inom området äldres hälso- och sjukvård (in Swedish). Medicinska forskningsrådet (MFR), Stockholm.

Thorslund M., Norström T. \& Wernberg K. (1991) The utilization of home help in Sweden: a multivariate analysis. Gerontologist 31, 116-119.

Tibblin G., Bengtsson C., Furunes B. \& Lapidus L. (1990) Symptoms by age and sex. The population studies of men and women in Gothenburg, Sweden. Scandinavian Journal of Primary Health Care 8, 9-17.

World Health Organisation (1992) International Statistical Classification of Diseases and Related Health Problems. Volume 1, 10th revision. World Health Organisation, Geneva. 